\title{
Modern Seafloor Hydrothermal Systems: New Perspectives on Ancient Ore-Forming Processes
}

Sven Petersen, Berit Lehrmann, and Bramley J. Murton

KEYWORDS: Marine minerals; seafloor massive sulfides; exploration; drilling

Seafloor massive sulfides (SMS) are deposits of metal-bearing minerals that form on and below the seabed from the interaction of heated seawater with the oceanic crust. They have become a target of increased global exploration activity due to their presumed resource potential. Recent investigations have shown that these occurrences are more variable than previously thought and that this variability is not necessarily reflected in analogous volcanogenic massive sulfide deposits preserved in the ancient rock record. These geological differences also affect the geochemistry and size of the deposits. Current knowledge of the distribution, tonnage, and grade of seafloor massive sulfides does not, however, permit a rigorous assessment of their global resource potential due to the limitations in exploration and assessment technologies and our current understanding of their 3-dimensional characteristics.

\section{INTRODUCTION}

Modern seafloor massive sulfides (SMS) are widely considered to present possible future metal resources, a view reflected by recent and increasing levels of exploration activity by governments and industry that is also attracting concerned interest from the public. SMS form from processes that have shaped our ocean floor and planet over billions of years, as exemplified by the many deposits that once formed on the ancient ocean floor and are now found on land as a consequence of continental collision and mountain building. Many of 
these so-called volcanogenic massive sulfide (VMS) deposits have been mined for metals for thousands of years. VMS deposits, hosted in ancient and uplifted ocean crust on the island of Cyprus, were some of the earliest mined for copper. This was done on such a large scale by the Phoenicians that the island derived its name from the Greek word for copper 'Kuprios' and its Roman form 'Cyprium'.

It is now 40 years since modern seafloor hydrothermal systems were first discovered in the Galapagos Rift and East Pacific Rise. Over those four decades we have begun to recognize the diversity and complexity of modern hydrothermal systems and, as a consequence, start to realize that our understanding of the ancient deposits may be incomplete due to the long history of geological processes that obscure information related to their formation. The study of SMS, therefore, provides the opportunity to study the ancient deposits without the subsequent overprint of deformation and metamorphism.

We know that SMS (also known as 'black smoker' deposits) form as a consequence of the interaction of seawater with hot oceanic crust deep beneath the seabed. This usually occurs at volcanically active tectonic plate margins including mid-ocean spreading centers and along volcanic arcs (Hannington et al. 2005; Fig. 1). During this process, cold seawater penetrates through cracks in the seafloor, reaching depths of several kilometers, where it is heated to temperatures over $400^{\circ} \mathrm{C}$. The resulting chemical reactions generate a caustic fluid that is hot, slightly acidic and chemically reduced. This fluid leaches the surrounding rocks and becomes strongly enriched in dissolved metals and sulfur. Due to its lower density, this super-heated mineral-rich cocktail rises through the crust and emerges from the seafloor into the overlying water column through hydrothermal vents. These form hydrothermal vent 
fields that are commonly associated with "oases of life", harboring exotic chemosynthetic faunal communities (Fisher et al. 2007). Unlike nearly all other forms of life on earth, these animals derive their primary energy from the chemical cocktail forming the vent fluids rather than from sunlight. Most of the metals dissolved in the ascending vent fluids precipitate when they mix with cold seawater, resulting in black and white smoker chimneys and mounds of accumulated massive sulfide. It should be noted that most of the metals carried by the rising vent fluids to the seafloor are "lost" to the overlying ocean where they disperse over tens to hundreds of kilometers. Some of these metals precipitate as metalliferous sediments on the seafloor while the rest remain dissolved and are carried away by currents into the deep ocean (Resing et al. 2015; German and Seyfried 2014). Those metal-rich minerals that precipitate at the vents often form individual chimneys ranging from a few centimeters to $45 \mathrm{~m}$ in height. Over time, these collapse and the resulting sulfide debris accumulates to form sulfide mounds built on top of the underlying seafloor. These mounds constitute the main mass and tonnage of seafloor massive sulfide deposits. Their growth is not restricted to chimney collapse and includes complex processes such as dissolution and replacement within and below the mounds including the formation of mixtures of sulfide and altered host rock known as stock-works. High-temperature hydrothermal fluids may also dissolve early-formed sulfides and re-precipitate them at the cooler outer margins of the deposit. Collapse and mass-wasting of the mound's flanks forms mineral-rich sediments that are often deposited over a kilometer of more in the vicinity of many deposits. Over the years, variations of this simple deposit model have been described from the seafloor globally. However, some of the styles of active venting on the modern seafloor have not yet been identified in the ancient rock record on land. These include sites with pronounced contributions from magmatic volatiles and metals, ultramafic-hosted SMS deposits, those 
that result in seafloor lakes of liquid sulfur, and others that are characterized by venting of liquid carbon dioxide (de Ronde and Stucker 2015). In some cases, this could be related to their preservation potential. Biological processes on the seafloor may, for instance, consume native sulfur quickly leaving no trace of it in the ancient rock record.

\section{DISTRIBUTION OF ACTIVE AND INACTIVE VENT SITES}

So far, about 380 sulfide-bearing or high-temperature hydrothermal sites have been found throughout the modern global ocean indicating the widespread occurrence of this type of seafloor mineralization (Fig. 2). These are mainly active high-temperature hydrothermal vent fields that are restricted to the young and volcanically active parts of the ocean floor. For example, along the $67,000 \mathrm{~km}$ length of seafloor spreading centers, $60 \%$ of all deposits occur at mid-ocean ridges and $27 \%$ in back-arc basins. Only $13 \%$ of deposits are found along the $22,000 \mathrm{~km}$ of active submarine volcanic arcs and very few $(<1 \%)$ have been found at hotspot volcanoes, such as Hawaii. About three quarters of the known deposits are hydrothermally active and only one quarter are inactive. The bias towards hydrothermally active vent sites results from our current exploration technologies. These have been developed to find hydrothermally active sites by tracing their location from the physical and chemical anomalies as they disperse through the water column (Baker 2017). These indicators include particle-rich plumes, temperature anomalies, chemical signatures such as high concentrations of manganese and iron, changes in redox potential (Eh), and even gas bubbles. Traditional exploration methods involved laborious vertical profiling and sampling of the water column from ships. More recent surveys use a variety of sensors mounted on autonomous (robotic) underwater vehicles (AUVs) that significantly speed up investigations 
(Connelly et al., 2012; Kawada and Kasaya 2017). The efficiency of this approach has been demonstrated in the Okinawa Trough, where AUV surveying over the past four years have doubled the number of known active vent sites from 11 (found between 1988 and 2013) to 23 in 2017. Recent estimates (Beaulieau et al. 2015) indicate ca. 1,300 active hightemperature vent sites globally, of which about 1000 remain to be found.

While plume surveys have been, and still are, the primary tools for exploring for active hydrothermal systems, they fail to locate older and hydrothermally extinct seafloor massive sulfide deposits (eSMS; Fig. 3) due to their lack of distal water column signals. As a result, little is known about the occurrence and distribution of eSMS deposits, including those that may be located far from zones of active venting or that might be buried by sediments or lava. These eSMS occurrences, which have been through the complete hydrothermal cycle and reached their maximum size, are likely to be more abundant and larger than the hydrothermally active SMS sites that are still forming. As a result, eSMS are a current focus of global exploration for potential deep-sea mining sites (Petersen et al. 2016). In the past, eSMS have been detected in the vicinity of areas of known active venting by visual observations and often by pure chance (Cherkashev et al. 2013). Even now, there have been few systematic regional surveys for eSMS deposits and, as a result, only $27 \%$ of the known sulfide-bearing seafloor deposits are hydrothermally inactive. But there is compelling evidence that many more eSMS sites exist. For example, in a recent survey at the Endeavour Segment of the Juan de Fuca Ridge, northeastern Pacific Ocean, AUV-based high-resolution bathymetry was used to identify extinct sulfide chimneys and mounds. There, in only eight dives lasting 18-hours each, the number of chimneys and mounds discovered was quadrupled (Jamieson et al. 2014). This is especially noteworthy since this location is 
considered to be one of the best studied submarine hydrothermal fields known, having seen well over one hundred submersible and remotely operated vehicle (ROV) dives during the past 30 years. In a more recent study, an AUV-based survey in the Trans-Atlantic Geotraverse (TAG) area of the slow-spreading Mid-Atlantic Ridge indicated that about ten times more sulfide material is contained in eSMS deposits than in the well-known, active hydrothermal mound (Petersen et al. 2017). Taken together, these observations provide increasing evidence that eSMS deposits are far more common than previously thought and almost certainly comprise the vast majority of the modern-day SMS resource.

\section{METAL CONCENTRATIONS}

The resource potential of seafloor massive sulfides depends critically on their bulk chemical composition. Studies have shown this is highly variable on a regional scale (Table 1 ) and not all elements contained in the sulfides are of commercial interest (Monecke et al. 2016; Hannington et al. 2005). For example, compared with basalt-hosted deposits at mid-ocean ridges, SMS deposits at back-arc basins and arc volcanoes often contain higher concentrations of copper and zinc that makes them more economically attractive (Table 1). Gold and silver are also enriched in some deposits, especially back arc basins, volcanic arcs, and ultramafic-hosted mid-ocean ridge systems, reaching concentrations of several tens of parts per million (ppm) for gold and hundreds of ppm for silver. Certain trace elements, that are of growing importance for modern society, such as gallium, germanium, tellurium, selenium or indium, occur in lower concentrations (a few tens of ppm) but can be significantly enriched in some occurrences (Monecke et al. 2016). 
The bulk composition also varies greatly at the deposit scale and even in hand-specimen. This is often a reflection of the temperature-controlled solubility of many metals. Copperrich minerals (chalcopyrite and isocubanite) typically form high-temperature cores to chimneys and mounds (Fig. 4). The cooler outer parts of the deposits comprise minerals rich in iron (pyrrhotite, pyrite, and marcasite) and zinc (sphalerite and wurtzite) together with various silicates and/or sulfates. These mineral assemblages are usually deposited at slightly lower temperatures as the hydrothermal fluid starts to mix with seawater. As a result of this heterogeneity, black smoker chimneys are not representative of the bulk compositions of the deposits. There is further evidence that the chemical composition of the interior of sulfide mounds as a whole differs significantly from samples collected from the seafloor. Investigations from ancient deposits as well as from modern seafloor sites, where the interior of the sulfide mounds is exposed or has been accessed by drilling, indicate enrichments of copper, zinc, gold and silver, is typical for grab samples taken from the surface of the mounds (Hannington et al. 2005). Published average chemical compositions of modern SMS are usually based on such surface grab samples taken from high-temperature chimneys and therefore do not represent a reliable base for resource estimates. This is largely a result of sampling having been driven by scientific research focused on understanding processes rather than an economic focus on resource potential. Suffice to say, the only viable economical assessment of a seafloor massive sulphide deposit (Nautilus Minerals Solwara 1) that includes more than 500 drillcores (Lipton, 2012).

\section{RESOURCE POTENTIAL}

Estimates of the global resource potential of seafloor massive sulfides vary widely. Cathles 
(2011) argued that "...the ocean floor is a giant VMS district with metal resources more than 600 times the total known VMS reserves on land and a copper resource which would last over 6,000 years at current production rates". In contrast, the amount of sulfide along the narrow neovolcanic zone at oceanic spreading centers, where new oceanic crust is produced, is estimated at 600 million tons globally (Hannington et al. 2011). This latter estimate was largely based on the known distribution of active hydrothermal vent sites at the time. Yet given the propensity for many more old and off-axis eSMS deposits remaining to be found, it is likely to be a significant underestimate of the total SMS resource potential. The difference between the two estimates is huge and there is obviously a need to improve global resource estimates through a better understanding of the distribution and occurrence of hydrothermally inactive systems.

Some of the resource estimate uncertainty lies in the enormous range in size (tonnage) of many modern SMS. These deposits are 3-dimensional with limited surface expression. Information from visual inspection, their surface morphology and sampling indicates that they may reach a thickness of several tens of meters. However, most known sites have a diameter of less than a few tens of meters and thus contain only a small amount of sulfide material (a few 1,000 tons to 10,000 tons; Hannington et al. 2011). Some occurrences on the global mid-ocean ridges, however, are known to contain between 100,000 tons and 1 million tons of massive sulfide. Very few are thought to be as large as 10 million tons. Hence, up until now, only a small number of known massive sulfide deposits are large enough to be considered of economic interest. This contrasts with the size distribution of ancient deposits, that are generally much larger (Hannington 2014). The data for land-based deposits, however, is strongly biased towards large deposits as it includes only data for deposits that 
were large enough to be mined, or to justify drilling, and many small sulfide occurrences are not included (Hannington et al., 2010). Additionally, current exploration technology on the modern seafloor is geared for detecting actively forming and commonly young deposits in the neovolcanic zone of mid-ocean ridges. Exploration in favorable geological settings, e.g. within sediment-filled basins, may show evidence for larger deposits on the modern seafloor.

It is probable that large and inactive or extinct sulfide deposits occur some tens to hundreds of kilometers away from the ridge axis, where they are buried below a few tens of meters of sediment or lava. The potential to find such 'off-axis' deposits opens up a vast area of the seafloor to future exploration. For example, extending the exploration effort to only $20 \mathrm{~km}$ on either side of the spreading axis increases the prospective area to 3.2 million $\mathrm{km}^{2}$ (Petersen et al. 2016; Fig. 5). However, without a distal signature, such as a geochemical or geophysical anomaly that is detectable over hundreds to thousands of meters away from deposit, and with only poorly constrained geophysical properties, such buried and inactive deposits are difficult to locate and evaluate. The resource potential also depends on the fate of eSMS deposits after they formed. The oldest dated sulfide deposits reach ages up to 220.000 years and are located along the Mid-Atlantic Ridge (Krasnov and Petersburgskoe; Cherkashov et al., 2013). We do not know, however, how long these massive sulfide deposits withstand seafloor weathering or if there are processes that protect them from oxidation. If not, they may fully oxidize, releasing their base metals back to seawater.

Without a better understanding of their size, structure, distribution and preservation, the global resource potential of inactive sulfide occurrences remains uncertain. Knowledge 
about the regional and local spatial controls of sulfide deposition are also still lacking. This is largely a reflection of the lack of high-resolution investigations away from the spreading axis. Large inactive deposits have been discovered in the past few years, especially associated with major tectonic structures at slow-spreading ridges (German et al. 2016;), opening up the possibility that these 'off-axis' deposits may be more common than we think. As a consequence of this potential seven applications for exploration for SMS have been approved by the International Seabed Authority in Jamaica, the authority responsible for managing activities in the deep-sea beyond national jurisdiction. All of these exploration areas $\left(10,000 \mathrm{~km}^{2}\right.$ each) lie along slow-spreading to intermediate-spreading ridges of the central Atlantic (two contracts and one application; Fig. 5) and central Indian Ocean (four contracts).

Our difficulty in exploring for off-axis eSMS deposits is a reflection of our inability to identify and assess deposits buried beneath even a few meters of sediments or lava. Yet there is some hope. The sediments themselves may provide a far-field geochemical halo around inactive deposits at a scale comparable to that of plume mapping for black smoker vents in the water column. Although sediment geochemistry has been a standard tool in marine geology for over a century, there have been few modern advances to adapt this technique to the search for marine mineral resources (Cherkashev et al., 2013). This contrasts with the search for ore deposits on land, where exploration geochemistry has achieved a high degree of sophistication, including the application of ultra-sensitive tracers such as mobile metal ions and pore-fluid gases to indicate sub-surface deposits (Cohen et al., 2010). Depth profiles of metals in seafloor sediments can be used to estimate the age of a source (based on sedimentation rates). But as yet there are few sensitive mineralogical, geochemical or 
isotopic tracers that have been tested that could be used as vectors towards metal deposits over lateral distances of 1-2 km, or buried at any depth below the seafloor.

\section{THE THIRD DIMENSION}

Because SMS deposits are 3-dimensional, and surface sampling is unlikely to be representative of the entire orebody, any resource estimate must incorporate depth information. As described above, tonnage calculations for most known seafloor deposits are based on surface estimates of lateral extent of hydrothermal precipitates, morphology and outcrop thickness. In many cases, these estimates are considered to overestimate their size and tonnage due to the incorporation of large areas that are thinly covered by hydrothermal material but do not contain sulfides (Hannington et al. 2011). Drilling, the routine approach for mineral resource assessment on land, is currently the only technology that provides reliable information on the subsurface composition of a mineral deposit. It has only been performed on a few SMS deposits but provides valuable insight into the interior composition.

Drilling by the Ocean Drilling Program in 1994 at the active TAG mound, which measures 200 $\mathrm{m}$ in diameter and $45 \mathrm{~m}$ in height, revealed a zoned deposit. Near-surface sulfide is enriched in copper, zinc, and gold while lower-grades occupy the interior (Humphris et al. 1995). This finding is important as it further demonstrates the potential bias from surface sampling for any resource estimates. Elsewhere, drilling SMS sites covered with thick sediment accumulation, either close to land or near explosive volcanic activity, indicated the occurrence of sub-seafloor replacement of clastic sediment and infilling of pore space by 
sulfides. This is caused by the sediment retaining a high proportion of metals from the vent fluid rather than being lost to the water column in a hydrothermal plume as is the case at sediment-free mid-ocean ridges. This, and the impermeable nature of the sediment blanket that is focusing fluid flow upwards, may result in the formation of large deposits that are mainly sub-seafloor. Such a setting is exemplified by drilling of the sediment-filled Middle Valley segment of the Juan de Fuca Ridge. Here, drilling intersected 100 meters of massive sulfides at the Bent Hill mound as well as several large stacked lenses of massive sulfide buried within the sediment at the ODP Mound (Zierenberg et al 1998). A conservative estimate indicates 9 million tons of sulfides are present in the Bent Hill deposit alone (Zierenberg et al 1998). The most comprehensive drilling of any SMS deposit has been done commercially at the Solwara 1 deposit in the Bismarck Sea, close to Papua New Guinea's New Ireland Province. The results revealed a reserve of 2.5 million tons of massive sulfide (Lipton 2012) at a site that is planned to be the first commercial deep-sea mining operation. A few other SMS have been drilled by seafloor rigs and returned important information on the composition of the upper few meters of the deposits but this is insufficient for resource estimates (Petersen et al. 2016 and references therein). While all these drill sites are active hydrothermal systems, drilling of extinct deposits is required to better understand the fate of massive sulfides after hydrothermal activity has ceased and mass wasting as well as oxidation has affected them.

It was therefore an important step when, in 2016, three inactive sulfide mounds located several kilometers away from the active TAG mound were drilled within the framework of the EU-funded Blue Mining project (Murton et al. 2017). All three sites show a similar distribution of rock types with depth that provides important information on the difference 
between active and inactive vent sites in this area. The eSMS mounds are characterized by a superficial cover of pelagic calcareous sediment overlying an unconsolidated layer of Feoxyhydroxides (Murton et al. 2017). These are underlain by a coherent and dense layer of red-colored silica-rich 'jasper', up to 5 meters thick, that overlays massive sulfide. The association of thick iron-silica-rich strata overlying sulfides is well documented for ancient sulfide deposits preserved in the geological record on land, such as the "tetsusekiei" cherts from the Kuroko deposits in Japan and from hydrothermal cherts and jaspers from the Iberian Pyrite Belt (Leistel et al. 1997; Barriga and Fyfe, 1988; Scott et al. 1983). However, it has not previously been observed beneath the modern seafloor. These coherent 'jasper' layers appear to be a common product, formed during the waning (cooling) stage of the hydrothermal cycle. As a result, they form an impermeable 'cap' that protects the underlying massive sulfide ore body from oxygen-rich seawater and subsequent dissolution. Hence the 'jasper cap' may play an important role in preserving sulfide deposits as a mineral resource once hydrothermal circulation ceases and they are transported away from the ridge axes by seafloor spreading.

\section{FUTURE EXPLORATION AND ASSESSMENT METHODOLOGY}

The growing body of evidence to indicate the resource potential of extinct and off-axis SMS deposits is a stimulus for the development of techniques to rapidly explore for them. Recent bathymetric mapping of $47 \mathrm{~km}^{2}$ of the TAG Hydrothermal Field, at a resolution of $2 \mathrm{~m}$ to 0.5 $\mathrm{m}$, by an AUV identified a number of inactive seafloor massive sulfide occurrences (Petersen et al., 2017). Such high-resolution AUV-based mapping of the seafloor with co-registered 
acoustic backscatter imagery, magnetic-field and self-potential data seems to be the only way to survey larger areas of the seafloor fast, efficiently and relatively cheaply. Yet despite covering $47 \mathrm{~km}^{2}$ during a single cruise, this represents only a fraction of the $10,000 \mathrm{~km}^{2}$ that a contractor to the International Seabed Authority is required to survey in the 15 year lifetime of the contract. Even if we only consider a $20 \mathrm{~km}$ corridor around a seafloor spreading axis, swarms of AUV working simultaneously seem to be the only realistic option for achieving any sort of well-informed global resource estimate.

Once sulfide occurrences have been detected, information on their sub-seafloor extent needs to be acquired. Seafloor drilling is both very expensive and difficult, although mandatory for mineral resources and reserve reporting to internationally recognized standards. Hence there is an urgent need to develop geophysical tools that help us estimate the thickness of deposits prior to drilling. Electromagnetic and seismic methods have recently been tested at the TAG hydrothermal Field and are starting to provide such information (Gehrmann et al 2017; Gil et al 2017; Jegen et al 2016). Future technology development is also needed to distinguish low-grade sulfides and barren rock from valuable ore during the drilling process itself, which could reduce the drilling time (Spagnoli et al. 2017). There is lots to do and no shortage of scientific and commercial opportunity!

\section{ACKNOWLEDGEMENTS}

Method development for exploration and resource assessment for marine minerals is supported by a grant from the EU-FP7-Project "Blue Mining: Breakthrough Solutions for the Sustainable Deep-Sea Mining Value Chain" under grant No. 604500. This grant also 
supported the recent cruises on RV Meteor (M127) and RRS James Cook (JC138) to the TAG area and is gratefully acknowledged. Additional support was provided by GEOMAR, Helmholtz Centre for Ocean Research Kiel, National Oceanography Centre Southampton, University of Southampton and British Geological Survey (Nottingham and Edinburgh). Helpful reviews by Fernando Barriga and Georgy Cherkashev and commenting by the guest editor Paul Lusty are gratefully acknowledged.

\section{REFERENCES}

1. Baker ET (2017) Exploring the ocean for hydrothermal venting: New techniques, new discoveries, new insights. Ore Geology Reviews, 86:55-69.

2. Barriga FJAS and Fyfe WS (1988) Giant pyritic base-metal deposits: the example of Feitais (Aljustrel, Portugal). Chemical Geology 69:331-343.

3. Beaulieu SE, Baker ET, German CR (2015) Where are the undiscovered hydrothermal vents on oceanic spreading ridges? Deep Sea Research Part II, 121:202-212.

4. Cathles LM (2011) What processes at mid-ocean ridges tell us about volcanogenic massive sulfide deposits. Mineralium Deposita, 46:639-657.

5. Cohen DR, et al., (2010) Major advances in exploration geochemistry, 1998-2007. Geochemistry: Exploration, Environment, Analysis, 10:3-16.

6. Connelly et al. (2012) Hydrothermal vent fields and chemosynthetic biota on the world's deepest seafloor spreading centre. Nature Communications, Dol:10.1038/ncomms1636

7. de Ronde CEJ, Stucker VK (2015) Seafloor hydrothermal venting at volcanic arcs and backarcs. In: Encyclopedia of Volcanoes, pp 823-849.

8. Fisher CR, Takai K, Le Bris N (2007) Hydrothermal vent ecosystems. Oceanography, 20:14-23.

9. Gehrmann R, Tan I, Minshull T, et al (2017) Massive sulphide exploration with controlled source electromagnetics at the Mid-Atlantic Ridge. Marelec Conference Liverpool, UK. June 27 - 30, 2017.

10. German CR, Seyfried WE Jr (2014) Hydrothermal Processes. In: Treatise on Geochemistry, 2:191-233

11. German CR, Petersen S, Hannington MD (2016) Hydrothermal exploration of midocean ridges: Where might the largest sulfide deposits be forming? Chemical Geology, 420:114-126. 
12. Gill A, Vardy M, Minshull T, et al (2017) How to identify extinct seafloor massive sulphides by using OBS wide-angle data - A case study from the Blue Mining project in the TAG hydrothermal field. Proceedings of the 46th Underwater Mining Conference, 24-26 September 2017, Berlin, Extended abstract

13. Hannington MD, de Ronde CD, Petersen S (2005) Sea-floor tectonics and submarine hydrothermal systems. Economic Geology, 100th Anniversary Volume: 111-141.

14. Hannington MD, Jamieson J, Monecke T, et al (2010) Modern sea-floor massive sulfides and base metal resources: toward an estimate of global sea-floor massive sulfide potential. Economic Geology Special Publication, 15:317-338.

15. Hannington M, Jamieson J, Monecke T, et al (2011) The abundance of seafloor massive sulfide deposits. Geology, 39:1155-1158.

16. Humphris SE, Herzig PM, Miller DJ, et al (1995) The internal structure of an active sea-floor massive sulfide deposit. Nature, 377:713-716.

17. ISA (2017) International Seabed Authority: Selected decisions and documents of the 23 session, ISBN: 978-976-8241-57-3.

18. Jamieson JW, Clague DA, Hannington MD (2014) Hydrothermal sulfide accumulation along the Endeavour Segment, Juan de Fuca Ridge. Earth and Planetary Science Letters, 395:136-148.

19. Jegen M, Hölz S, Safipour R, et al (2016) Exploration of buried SMS deposits with time domain EM. EAGE Near Surface Geoscience Conference, Barcelona, Spain. September 2016. Extended abstract.

20. Kawada Y, Kasaya T (2017) Marine self-potential survey for exploring seafloor hydrothermal ore deposits. Scientific Reports 1-12. doi: 10.1038/s41598-017-139200

21. Leistel JM, Marcoux E, Deschamps Y (1997) Chert in the Iberian pyrite belt. Mineralium Deposita, 33:59-81.

22. Lipton I (2012) Mineral Resource Estimate Solwara Project, Bismarck Sea, PNG. NI43101, Technical Report for Nautilus Minerals Inc.

23. Monecke T, Petersen S, Hannington MD, et al (2016) The minor element endowment of modern sea-floor massive sulfides and comparison with deposits hosted in ancient volcanic successions. Reviews in Economic Geology, 18:245-306.

24. Murton B, Lusty, P, et al. (2017) Cruise report RRS James Cook JC138, Project Blue Mining, National Oceanography Centre, 198pp.

25. Petersen S, Krätschell A, Augustin N, et al (2016) News from the seabed - Geological characteristics and resource potential of deep-sea mineral resources. Marine Policy, 70:175-187.

26. Petersen S, Hannington M, Krätschell A (2017) Technology developments in the exploration and evaluation of deep-sea mineral resources. Annales des Mine: Responsabilite et Environnement, 85:14-18.

27. Resing JA, Sedwick PN, German CR, et al (2015) Basin-scale transport of hydrothermal dissolved metals across the South Pacific Ocean. Nature, 523:200-203.

28. Scott SD, Kalogeropoulos SI, Shegelski RJ, et al (1983) Tuffaceous exhalites as exploration guides for volcanogenic massive sulphide deposits. Journal of Geochemical Explortaion, 19:500-502.

29. Spagnoli G, Weymer BA, Jegen M, et al (2017) P-wave velocity measurements for preliminary assessments of the mineralization in seafloor massive sulfide mini-cores during drilling operations. Engineering Geology, 226:316-325.

30. Zierenberg RA, Fouquet Y, Miller DJ, et al (1998) The deep structure of a sea-floor 
hydrothermal deposit. Nature, 392:485-488.

Figure captions

Figure 1: Figure 1: Block models of the major tectonic settings for modern seafloor hydrothermal activity. a) Typical fast- to intermediate-spreading ridge where hydrothermal activity is located along the spreading axis. b) Volcanic arc/back arc system with contributions of volatiles to the hydrothermal systems from the subducting slab as well as from magma chambers (Graphics: M. Klischies, GEOMAR).

Figure 2: Global distribution of active (red) and inactive (yellow) seafloor massive sulfide sites. Sites where no detailed information on activity is given are marked by white dots. $(\mathrm{N}=378$; source GEOMAR). Exclusive economic zones are indicated.

Figure 3: Image of inactive chimney topping an inactive mound in the TAG hydrothermal field (New Mound; source HYBIS, NOC).

Figure 4: a) Typical section through a black smoker vent showing the copper-rich interior dominated by chalcopyrite and a zinc-rich outer part with abundant sphalerite. b) Early chalcopyrite (cpy) is lined by grey sphalerite and overgrown by massive pyrite (py). c) Complex intergrowth of bornite (bn) overgrown by chalcopyrite (cpy) and sphalerite (sl). Bornite is oxidized to covellite (blue) along cracks. d) Native gold (bright yellow) intergrown with bornite (bn) and chalcopyrite (cpy). Scale bar in b-d is $100 \mu \mathrm{m}$.

Figure 5: Map showing a 20-km corridor around mid-ocean ridges in the central Atlantic. Adding a corridor like this may be needed to assess the potential for inactive sulfide 
occurrences that are not too deeply covered by sediments or lava to be found with current technologies. The global prospective area would increase to over 3 million $\mathrm{km}^{2}$ (Petersen et al. 2017). Current exploration contract blocks for Russia (green), France (yellow), and the application area for Poland (white; ISA 2017) are indicated as are the locations of known active (red stars) and inactive vent fields (yellows stars).

Table 1: The mean metal content of SMS occurrences with respect to their tectonic setting (source GEOMAR). Note that the concentration of the trace metals gold and silver is given in parts per million (ppm). $\mathrm{N}=$ number of deposits for which chemical data is included.

Abbreviations: $\mathrm{MOR}=$ Mid-Ocean Ridges.

\begin{tabular}{|l|r|r|r|r|r|r|r|}
\hline Setting & N & $\begin{array}{r}\mathrm{Cu} \\
\text { wt.\% }\end{array}$ & $\begin{array}{r}\mathrm{Zn} \\
\text { wt.\% }\end{array}$ & $\begin{array}{r}\mathrm{Pb} \\
\text { wt.\% }\end{array}$ & $\begin{array}{r}\mathrm{Fe} \\
\text { wt.\% }\end{array}$ & $\begin{array}{r}\mathrm{Au} \\
\mathrm{ppm}\end{array}$ & $\begin{array}{r}\mathrm{Ag} \\
\mathrm{ppm}\end{array}$ \\
\hline Sediment-free MOR & 60 & 4.2 & 8.2 & 0.2 & 26.0 & 1.2 & 92 \\
\hline Ultramafic-hosted MOR & 12 & 13.2 & 7.1 & $<0.1$ & 24.7 & 6.6 & 66 \\
\hline Sediment-hosted MOR & 4 & 0.9 & 3.1 & 0.4 & 32.2 & 0.4 & 65 \\
\hline Intraoceanic back arc & 36 & 2.6 & 17.3 & 0.7 & 14.9 & 4.2 & 188 \\
\hline Transitional back-arcs & 13 & 6.6 & 17.4 & 1.5 & 8.8 & 12.9 & 321 \\
\hline Intracontinental rifted arc & 6 & 2.7 & 14.0 & 8.0 & 5.8 & 3.5 & 2091 \\
\hline Volcanic arcs & 17 & 3.9 & 8.9 & 1.8 & 11.0 & 10.0 & 204 \\
\hline
\end{tabular}



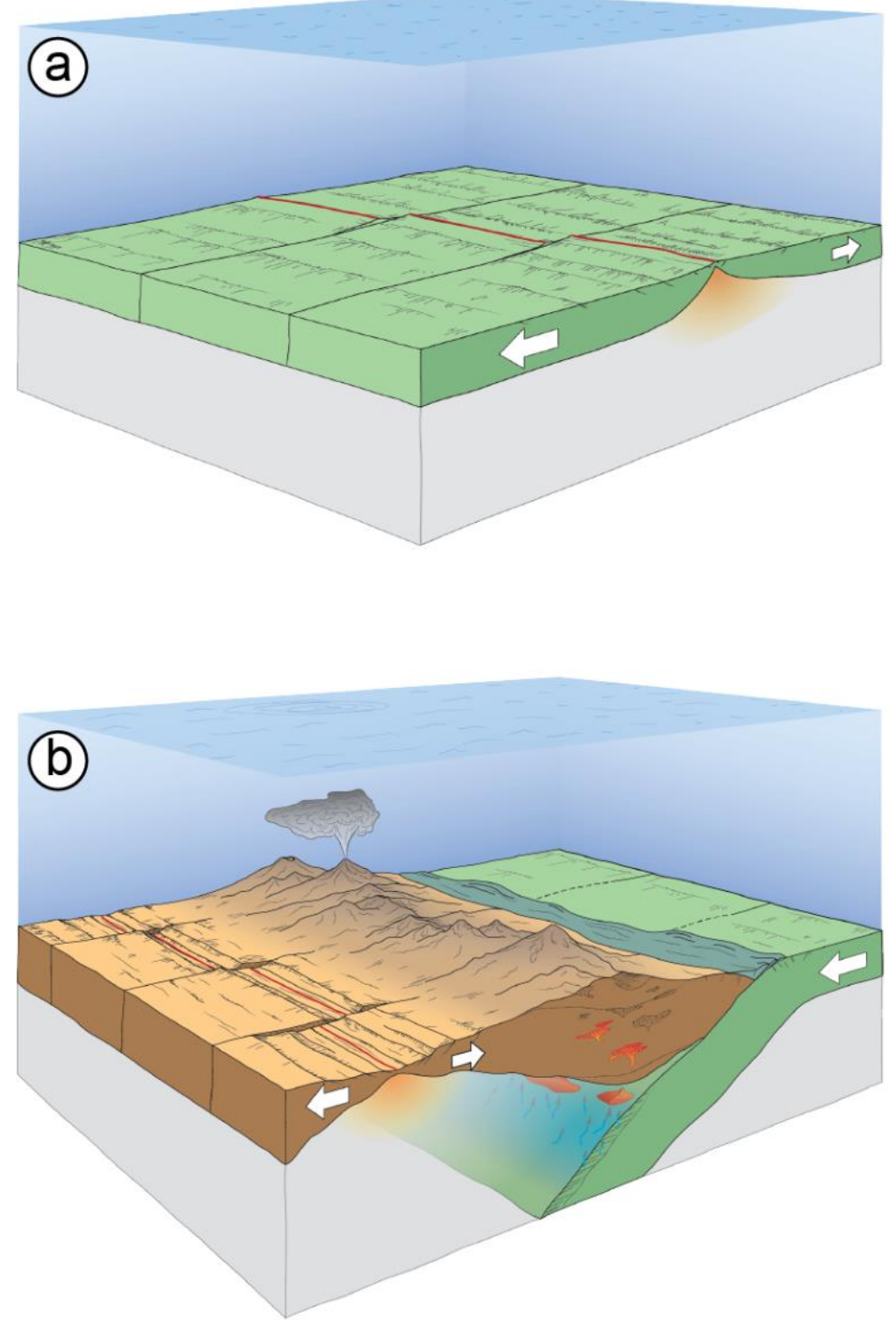

Figure 1: Block models of the major tectonic settings for modern seafloor hydrothermal activity. a) Typical fast- to intermediate-spreading ridge where hydrothermal activity is located along the spreading axis. b) Volcanic arc/back arc system with contributions of volatiles to the hydrothermal systems from the subducting slab as well as from the magma chambers (Grafic: M. Klischies, GEOMAR). 


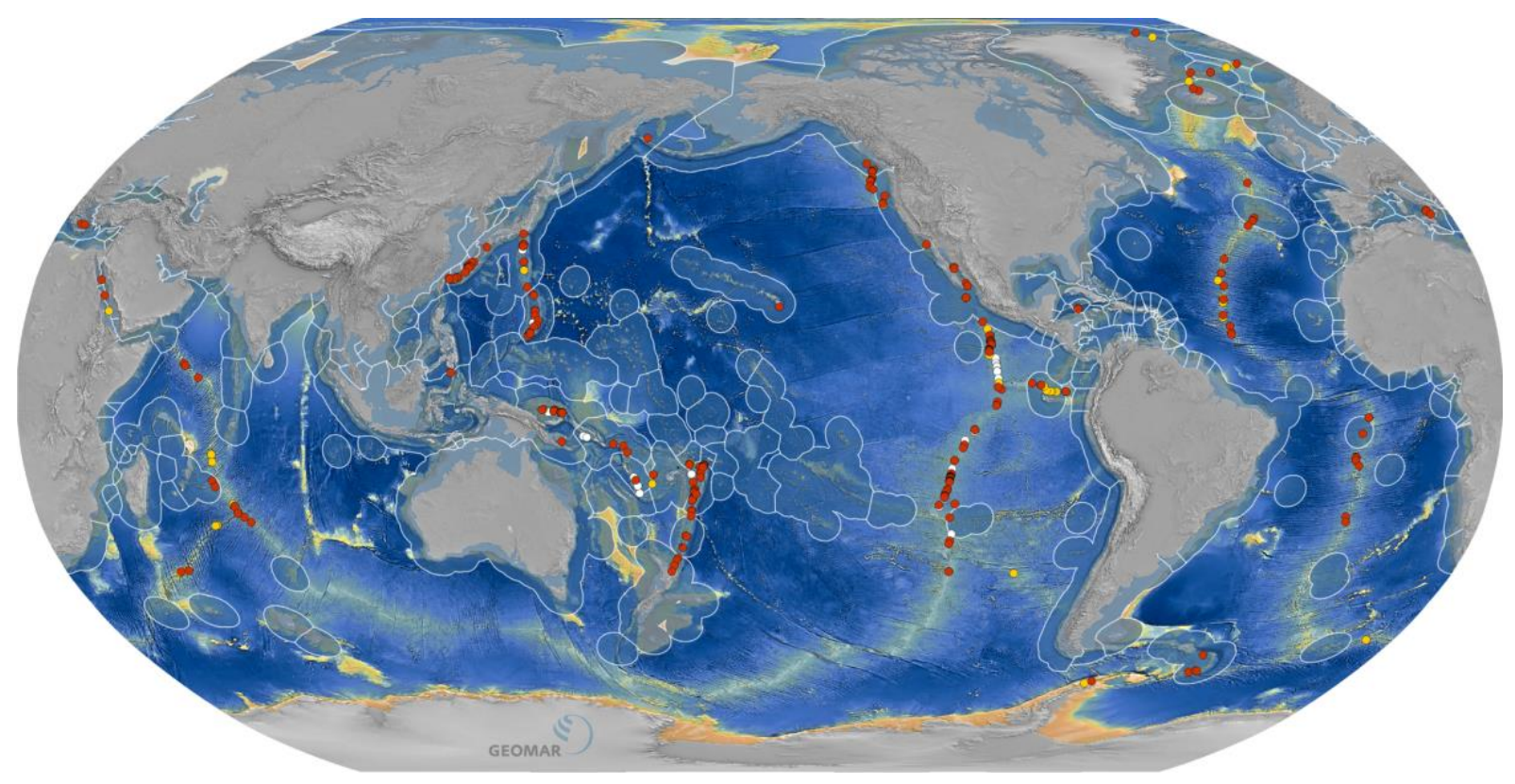

Figure 2: Global distribution of active (red) and inactive (yellow) seafloor massive sulfide sites. Sites where no detailed information on activity is given are marked by white dots. $(\mathrm{N}=378$; source GEOMAR). Exclusive economic zones are indicated. 


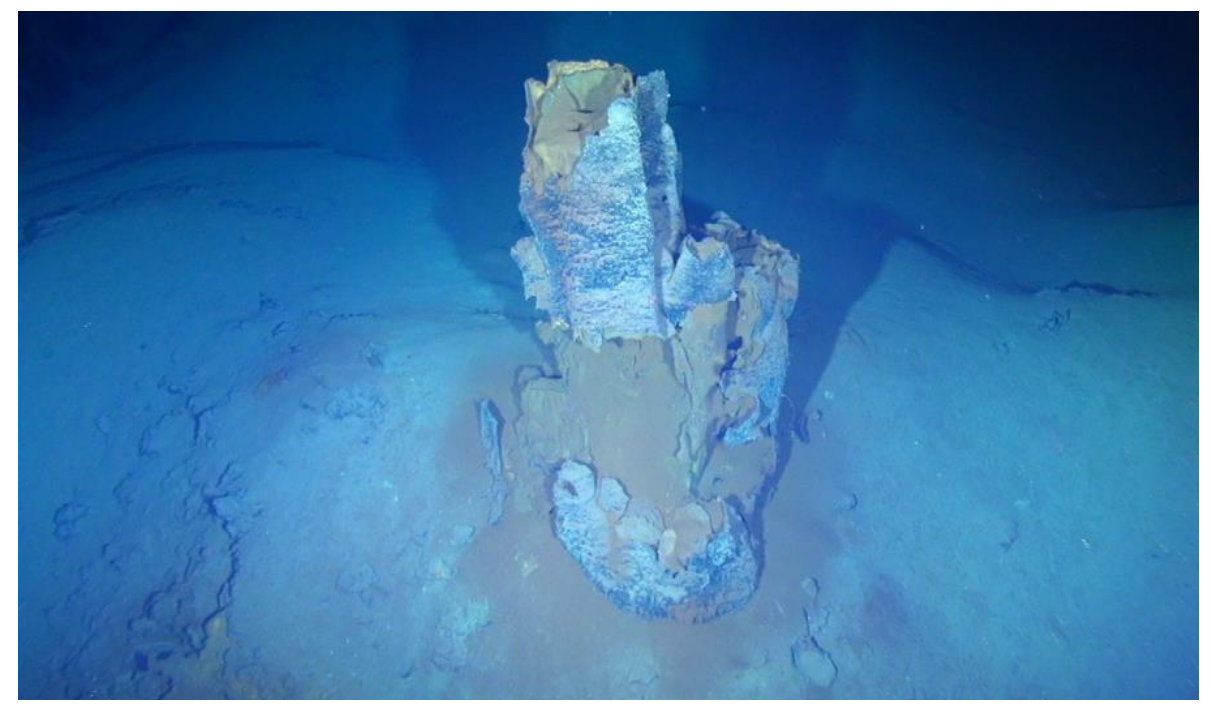

Figure 3: Image of inactive chimney topping an inactive mound in the TAG hydrothermal field (New Mound; source HYBIS, NOC). 

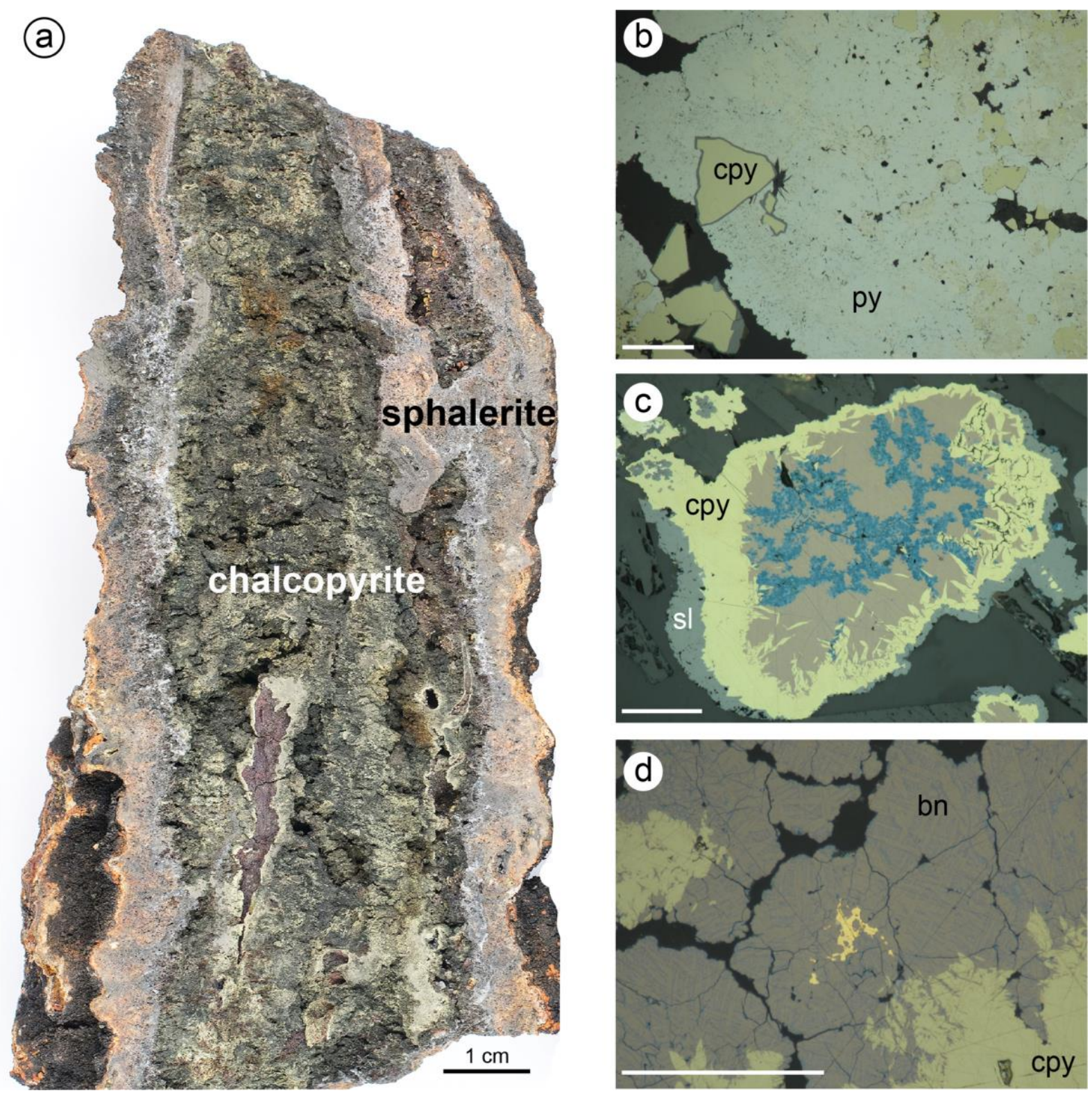

Figure 4: a) Typical section through a black smoker vent showing the copper-rich interior dominated by chalcopyrite and a zinc-rich outer part with abundant sphalerite. b) Early chalcopyrite (cpy) is lined by grey sphalerite and overgrown by massive pyrite (py). c) Complex intergrowth of bornite (bn) overgrown by chalcopyrite (cpy) and sphalerite (sl). Bornite is oxidized to covellite (blue) along cracks. d) Native gold (bright yellow) intergrown with bornite (bn) and chalcopyrite (cpy). Scale bar in b-d is $100 \mu \mathrm{m}$. 


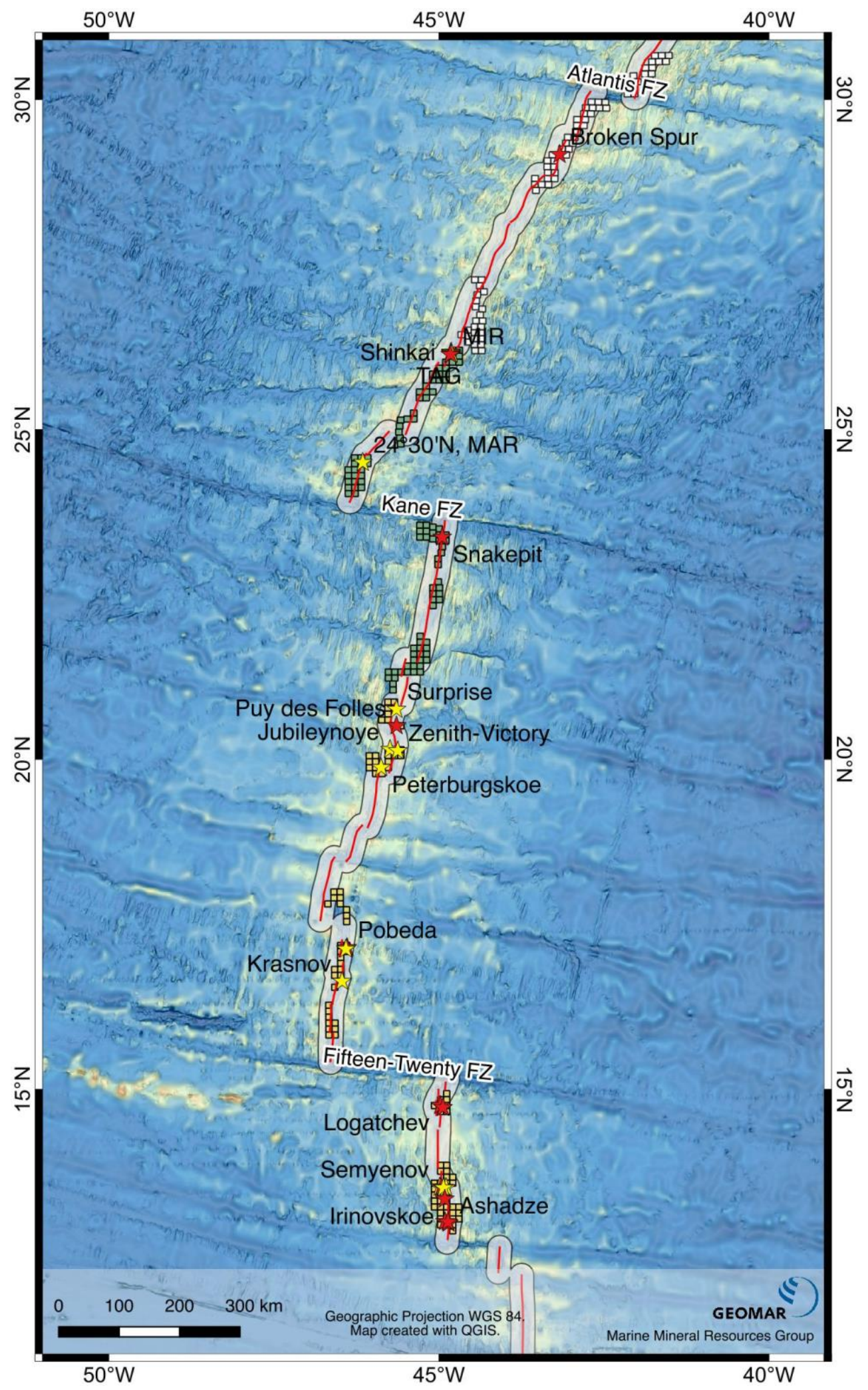

Figure 5: Map showing a 20-km corridor around mid-ocean ridges in the central Atlantic. Adding a corridor like this may be needed to assess the potential for inactive sulfide occurrences that are not too deeply covered by sediments or lava to be found with current technologies. The global prospective area would increase to over 3 million $\mathrm{km}^{2}$ (Petersen et al. 2017). Current exploration contract blocks for Russia (green), France (yellow), and the application area for Poland (white; ISA 2017) are indicated as are the locations of known active (red stars) and inactive vent fields (yellows stars). 